\title{
Structure Analysis of Self-Kinasing Ribozyme
}

\author{
Bongrae Cho \\ Department of Applied Chemistry, Cheongju University, Cheongju 360-764, Korea.E-mail: brcho@cju.ac.kr \\ Received March 3, 2006
}

Key Words : RNase T1, RNase V1, Kethoxal, Fe(II)-EDTA

A kinase ribozyme selected from a random-sequence RNA library which was based on a ATP aptamer sequence, can catalyze transfer of the thiophosphate from ATP- $\gamma-\mathrm{S}$ to its own $5^{\prime}$ hydroxyl end in the presence of oligonucleotide effector which is complementary to its 3' primer binding sequence (PBS) used in the amplification steps during the original selection for activity. ${ }^{1,2}$ Omitting the oligonucleotide reduced the observed catalytic rate constant $\left(k_{\text {obs }}\right)$ by $10^{3}$ to $10^{6}$-fold, so the deoxyoligonucleotide effector is necessary for its activity. The activator helix formed by PBS and the oligo effector is connected by a 5 nt "linker" region to the substrate-binding internal guide sequence and stabilizes a long-range base-paring interaction between the 5 nuclotides of the linker and those closer to the catalytic core. In this study, RNA structural probes such as enzymes and chemicals was exploited to get the information for the structure of the kinase ribozyme.

Enzymes which were used in this work for probing RNA structure in solution, were double-strand-specific RNase V1, single-strand-specific nuclease S1 and RNase T1 which has a specificity for a guanine in single strand region, and kethoxal (3-ethoxy-1,1-dihydroxy-2-butanone) which modify the $\mathrm{N} 1$ and $\mathrm{N} 2$ of guanine in the single strand. ${ }^{3-5}$ Enzymes whose size are above $100 \AA$ have an accessibility problem to target RNA because of their big size. To overcome this problem, hydroxyl radical or kethoxal whose size are below $10 \AA$ A were used.

As the kinase ribozyme was originally selected at $50 \mathrm{mM}$ $\mathrm{Mg}^{2+}$, the RNA structure was probed in the presence of 50 $\mathrm{mM} \mathrm{Mg}{ }^{2+}$ with RNase T1, RNase V1 and nuclease S1 (Fig. 1). G20, G30, G32, G34, G45, G46, G53, and G54 were cleaved by RNase T1, especially with strong cleavages at G62, G63 and G64, suggesting that these guanines are in a single-strand region of the secondary structure model of kinase ribozyme.

Kethoxal can not modify guanines which are in the double strand region but modify guanines which are in the single strand region. As RNase T1 treatment of the RNAs modified with kethoxal makes bands corresponding to guanines in the single strand but not guanines in the double strand regions on autoradiogram. Kethoxal modification of the kinase ribozyme, followed by RNase T1 treatment was performed both in the absence and the presence of ATP, a substrate of kinase ribozyme (Fig. 2). G30, G32, G34, G45, G46, G53 and G54 appeared as bands in the presence of ATP, suggesting that they are located in double strand in the

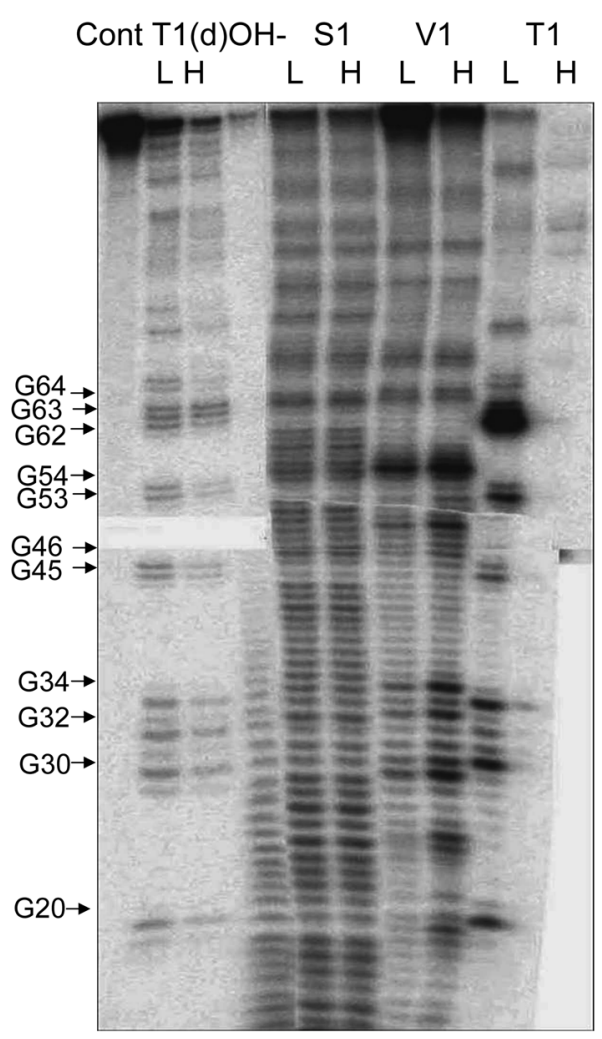

Figure 1. Enzymatic probing of ribozyme labeled at the 5'-end. The RNA was partially digested with Nuclease S1 or RNase V1 or RNase $\mathrm{T} 1$ in the presence of $50 \mathrm{mM} \mathrm{Mg}{ }^{2+}$ concentration with activating oligomer. The nucleotides cleaved by RNase $\mathrm{T} 1$ are indicated by arrows. Lane Cont, control; lane $\mathrm{T} 1(\mathrm{~d})$, the denatured RNA treated with RNase T1; lane $\mathrm{OH}-$, partial alkaline ladder. L and $\mathrm{H}$ under each enzyme lane mean low and high number of units of each enzyme, respectively.

presence of ATP, but in single strand region in the absence of ATP. This result is consistent with that of Figure 1. Therefore, it is likely that helix P2 and helix P3 flanking the catalytic core, ATP-binding motif, can be stabilized in the presence of ATP.

Exposed nucleotides are damaged by hydroxyl radical $(\mathrm{OH})$ while nucleotides involved in tertiary contacts are protected from damage, making it a favorable approach for establishing exterior/interior relations for RNA. ${ }^{6-12}$ Usually radicals are generated from Fe(II)-EDTA with hydrogen peroxide $\left(\mathrm{H}_{2} \mathrm{O}_{2}\right)$ and ascorbate (or DTT) is added to reduce $\mathrm{Fe}(\mathrm{III})$ to $\mathrm{Fe}$ (II). In this radical reaction with RNA, hydrogen 


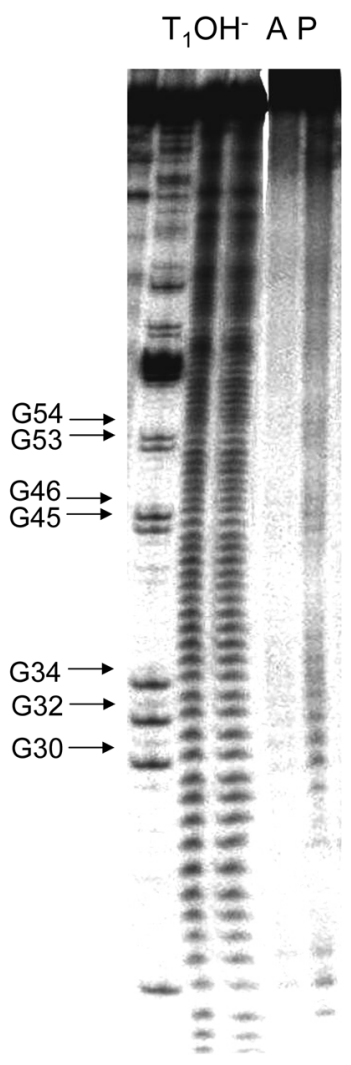

Figure 2. RNase T1 cleavage sites of ribozyme labeled at the 5'end, following kethoxal modification. Kethoxal modification reaction was performed at the $50 \mathrm{mM} \mathrm{Mg}{ }^{2+}$ concentration in the absence and presence of $10 \mathrm{mM}$ ATP. The cleaved guanines which are in double strand, are indicated by arrows. A and P indicate the absence and the presence of ATP, respectively. Notations are as described in the legend to Figure 1.

abstraction from the ribose 4 ' carbon leads to strand scission. The cleavage reaction of the kinase ribozyme with hydroxyl radical was quenched with thiourea and the products were analyzed by PAGE. Hydroxyl radical cleavage reaction was performed both in the absence and the presence of ATP (Fig. 3). Sequence C88GGGG92 was cleaved more strongly in the presence of ATP than at the absence of ATP, suggesting that this sequence which is conserved in ATP aptamers and close to catalytic core, is exposed by ATP in the secondary structure model of kinase ribozyme molecule.

In conclusion, the structure of kinase ribozyme was analyzed in solution with probes such as RNase T1, RNase $\mathrm{V} 1$, kethoxal and hydroxyl radical generated from $\mathrm{Fe}^{2+} /$ EDTA $/ \mathrm{H}_{2} \mathrm{O}_{2}$. The result suggested that 1) helices $\mathrm{P} 2$ and $\mathrm{P} 3$ are stabilized in the presence of ATP, 2) nucleotides in loop $\mathrm{J} 3 / 2$ are exposed in the presence of ATP, and 3) single strand region L3, which does not play an important role in the activity of this kinase ribozyme, is also exposed in the secondary structure model.

\section{Experimental Section}

Preparation of RNA. The kinase ribozyme strand was

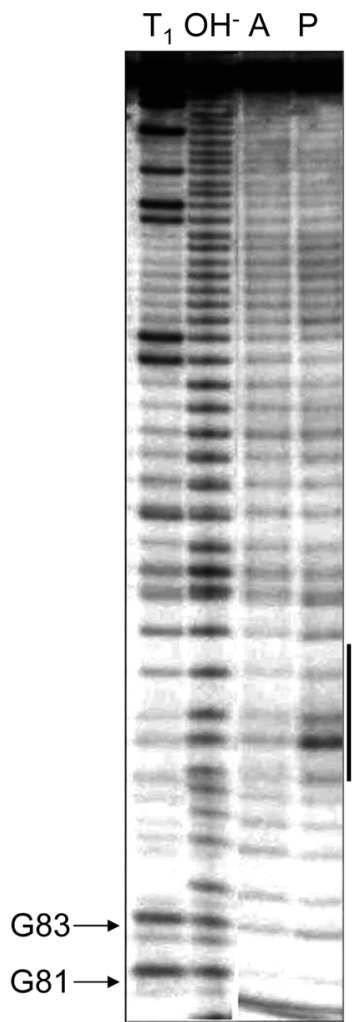

Figure 3. Hydroxyl radical cleavage sites of ribozyme labeled at the 5 '-end. The cleavage reaction was performed at the $50 \mathrm{mM}$ $\mathrm{Mg}^{2+}$ concentration in the absence and the presence of $10 \mathrm{mM}$ ATP. The strong cleavages were occurred in the presence of $10 \mathrm{mM}$ ATP, compare with the absence of ATP and their cleavage sites were denoted by bar. A and P indicate absence and presence of ATP, respectively. Notations are as described in the legend to Figure 1.

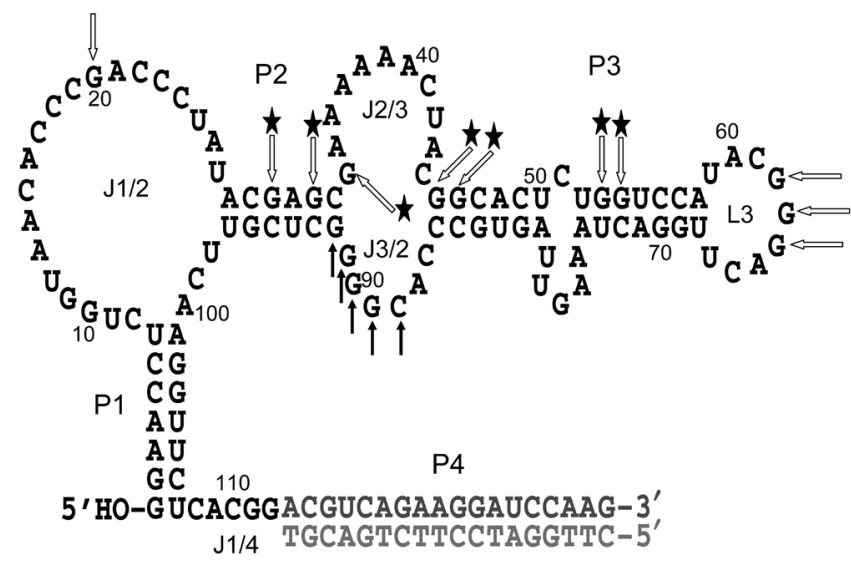

Figure 4. Schematic representation of possible secondary structure of kinase ribozyme. Open arrows indicate the sites cleaved by RNase T1 at the absence of ATP, and stars and filled arrows indicate guanines (in the double) not modified with kethoxal and the sites cleaved by hydroxyl radical in the presence of ATP, respectively.

synthesized by run-off in vitro transcription with T7 RNA polymerase from the DNA template to which the T7 promoter was annealed. The resulting RNA was treated with CIP (calf intestinal alkaline phosphatase) to remove $5^{\prime}$ end 
phosphate and then labeled at the $5^{\prime}$ end using $\left[\gamma^{32} \mathrm{P}\right]$ ATP and T4 polynucleotide kinase.

Enzymatic cleavage reaction. 5'-terminal radiolabeled kinase ribozyme strand and activating DNA oligomer were heated in KCl/Pipes buffer $(200 \mathrm{mM} \mathrm{KCl}$ in $150 \mathrm{mM}$ Pipes$\mathrm{KOH}, \mathrm{pH} 7.0)$ at $90{ }^{\circ} \mathrm{C}$ for $2 \mathrm{~min}$ and allowed to cool to RT $\left(\sim 21{ }^{\circ} \mathrm{C}\right)$. These were adjusted to a final concentration of 50 $\mathrm{mM} \mathrm{MgCl}$. Then 0.1-1 unit of nuclease S1 or 0.001-0.01 unit of RNase V1 or 0.1-1 unit of RNase T1 was added to the above mixture and then the reaction mixture was incubated for $20 \mathrm{~min}$ at RT. The cleavage products were recovered by ethanol precipitation and separated on a $12 \%$ polyacylamide gel in $90 \mathrm{mM}$ Tris-borate $(\mathrm{pH} 8.3)$ and 2.5 mM EDTA containing $7 \mathrm{M}$ urea.

Kethoxal modification and RNase $\mathrm{T} 1$ cleavage reaction. 5'-end labeled RNA and activating DNA oligomer were renatured as above. The renatured mixture was adjusted to a final concentration of $10 \mathrm{mM}$ (or $0 \mathrm{mM}$ ) ATP in the presence of $50 \mathrm{mM} \mathrm{MgCl}_{2} .1 \mathrm{uL}$ of kethoxal was dissolve in $10 \mathrm{uL}$ of $100 \%$ ethanol and $10 \mathrm{uL}$ of $70 \%$ ethanol and $1-2$ $\mathrm{uL}$ of dissolved kethoxal solution was added to the renatured mixture, which was incubated for 20-25 min at RT. The modified products were recovered by ethanol precipitation and then digested with RNase $\mathrm{T} 1$ for $15 \mathrm{~min}$ in the presence of $7 \mathrm{M}$ urea. The cleavage mixtures were subject to a denaturing $12 \%$ polyacylamide gel electrophoresis.

$\mathrm{Fe}^{2+} / \mathbf{E D T A} / \mathrm{H}_{2} \mathrm{O}_{2}$ cleavage reaction. 5'-end labeled RNA and activating DNA oligomer were renatured as above. The renatured mixture was adjusted to a final concentration of 10 $\mathrm{mM}$ (or $0 \mathrm{mM}$ ) ATP in the presence of $50 \mathrm{mM} \mathrm{MgCl}_{2} .1 \mathrm{uL}$ of $0.4 \mathrm{mM} \mathrm{Fe}\left(\mathrm{NH}_{4}\right)_{2}\left(\mathrm{SO}_{4}\right)_{2} \cdot 6 \mathrm{H}_{2} \mathrm{O}$ (freshly prepared), $1 \mathrm{uL}$ of $0.8 \mathrm{mM}$ EDTA, $\mathrm{pH} 8.0,1 \mathrm{uL}$ of $0.3 \% \mathrm{H}_{2} \mathrm{O}_{2}$ and $1 \mathrm{uL}$ of 1 $\mathrm{mM}$ DTT were added to the mixture and the reaction mixture was incubated for 5-10 min at RT. The reaction was quenched by adding thiourea to $1.3 \mathrm{mM}$ and the cleavage products were recovered by ethanol precipitation and separated on a $12 \%$ polyacylamide gel containing $7 \mathrm{M}$ urea.

Acknowledgement. I appreciate Dr. Donald H. Burke (Department of Molecular Microbiology \& Immunology and Biochemistry, University of Missouri) for his helpful discussion.

\section{References}

1. Lorsch, J. R.; Szostak, J. W. Nature 1994, 371, 31

2. Lorsch, J. R.; Szostak, J. W. Biochemistry 1995, 34, 15315.

3. Brunel, C.; Romby, P. Methods in Enzymology 2000, 318, 3-21.

4. Ko, J.-H.; Cho, B.; Ahn, J. K.; Lee, Y.; Park, I. Bull. Korean Chem. Soc. 1999, 20, 1335-1339.

5. Ko, J.; Lee, Y.; Park, I.; Cho, B. FEBS Lett. 2001, 508, 300-304.

6. Latham, J.; Cech, T. Science 1989, 45, 276-282.

7. Stern, S.; Moazed, D.; Noller, H. Methods Enzymol. 1988, 164, 481-489.

8. Murphy, F. L.; Cech, T. R. Biochemistry 1993, 32, 5291-5300.

9. Rangan, P.; Masquida, B.; Westhof, E.; Woodson, S. Proc. Natl. Acad. Sci. USA 2003, 100, 1574-1579.

10. Tsai, H.; Masquida, B.; Biswas, R.; Westhof, E.; Gopalan, V. J. Mol. Biol. 2003, 325, 661-675.

11. Barrera, A.; Pan, T. RNA 2004, 10, 482-493.

12. Bergman, N.; Lau, N.; Lehnert, V.; Westhof, E.; Bartel, D. P. RNA 2004, 10, 176-184. 